\title{
1 Crime and fear in public places
}

\section{Aim, scope and context}

\author{
Vania Ceccato, Juma Assiago \\ and Mabesh K. Nalla
}

\subsection{Introduction}

Safety is an essential dimension of urban sustainability. In a sustainable city, safety ensures each person a place to live free from danger but also has the possibility of movement that is essential to place attachment and one's quality of life (UN-Habitat, 2013, 2017, 2019). The adoption by member states of the 2030 Agenda for Sustainable Development (UN, 2019) and the New Urban Agenda have provided a global blueprint towards better connected, mixed use and compact cities and human settlements. Additionally, the adoption of UN system-wide Guidelines on Safer Cities and Human Settlements provides further guidance to national and local governments to plan and make cities and human settlements safer. The UN-Habitat's approach is premised on 'prevention' rather than reaction, to effectively address the complex challenges of urban insecurity, crime and violence. Placing public places and public transit availability, use and access at the center of the urban safety debate is a new way of understanding the role of cities and local governments in the prevention of crime and violence. Challenging traditional assumptions about urban crime and violence to make cities places of hope should influence global understanding of how individuals use and access the city in differentiated experiences.

No city environment reflects the meaning of urban life better than a public place. A public place, whatever its nature-a park, a mall, a train platform or a street corner-is where people pass by, meet each other, socialize and occasionally (only occasionally) become a victim of crime (Ceccato, 2016). The international research on environmental criminology and place-based crime prevention has long demonstrated how important the particular situational conditions of public places are to crime and citizens' perceived safety. Yet, what makes a public place safe remains open to debate.

With this book, we engage in this debate by submitting that crime and safety in public places are not issues that can be easily dealt with within the boundaries of a single discipline, such as criminology or urban planning. Rather, they require knowledge and practical examples from other disciplines. This edited volume also assembles a unique set of original research as chapters that deal with public place and the situational conditions of crime (Clarke, 1997) and 


\section{Vania Ceccato et al.}

fear, from the perspective of sociology, criminology, geography, architecture, urban planning, engineering, computer science, gender studies, transportation, and law enforcement. These studies cross traditional boundaries between disciplines yet share a number of important commonalities.

Overall, this discussion about safety in public places is not only an important issue for research but also for the vision and practices of long-term sustainability of cities (UN-Habitat, 2019). Promoting accessibility for all social groups in the city regardless of people's background is a key factor towards the realization of safe and sustainable cities and human settlements, using holistic, evidence-based and multidisciplinary approaches to urban safety and security.

This chapter provides an introduction to the theme of crime and fear in public places, the book's scope, steps taken in the making of the book, key definitions, and the synopsis of the chapters.

\subsection{Aim, scope and context}

The aim of the book is to illustrate the complexity of patterns of crime and fear in public places by providing examples of studies on these topics contextualized in different cities and countries around the world. All contributions add to our quest for safer, inclusive, resilient, equitable and sustainable cities and human settlements aligned to the Global 2030 Agenda for Sustainable Development (UN, 2019).

This is achieved by tackling five themes (Figure 1.1):

1 the nature of the city's structure as a backdrop for crime and fear (The environment),

2 the dynamics of people's daily routines and their transit safety (The movement),

3 the safety experienced by those who are most targeted by these offences in public places (The users' perspective),

4 the methodological challenges and advancements in the analysis of crime and fear (The Metrics), and,

5 the examples of current practices in promoting safety for different groups of society, both by academics and practitioners (The intervention).

Safety is one of the main concerns regarding public spaces. In fact, safety highly affects the use of a public place and its accessibility. Several environmental characteristics affect the safety of public places, yet it is safety perception that plays a significant role in making places appear safe or unsafe to people (Costamagna, Lind, \& Stjernström, 2019). Therefore, how cities are planned and designed has a major impact on an individual's safety (Ceccato, 2016). In this book, we provide examples, on the one hand, of public places that concentrate people and therefore offer crime opportunities. This is discussed in the cross-cutting theme The environment, which is focused on the city environment as the backdrop of crime and fear. Transportation nodes, parks, sports 

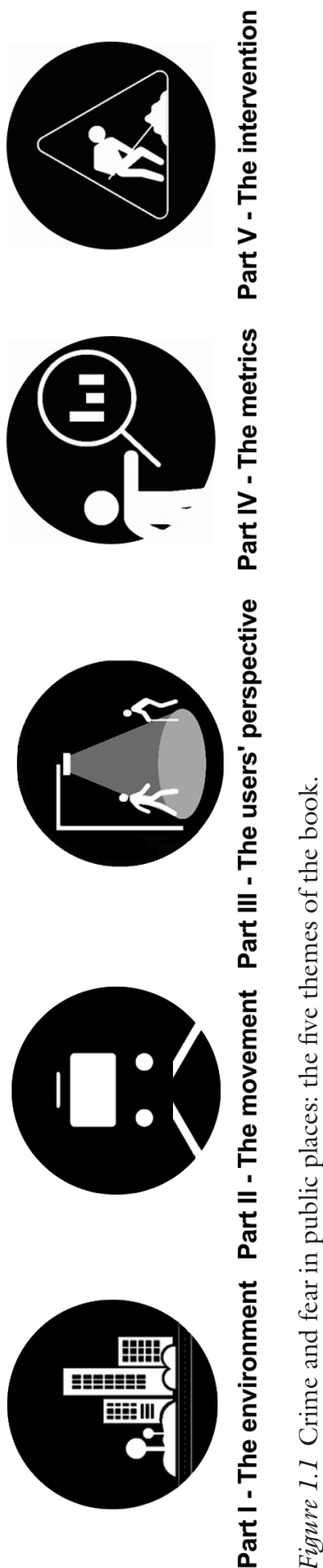


\section{Vania Ceccato et al.}

arenas, and university campuses illustrate the types of criminogenic conditions that might be at play in these environments. The environments where crime concentrates are different from other places in the city (Sherman, Gartin, \& Buerger, 1989), because they are crime hot spots, that is, they have the capacity to attract and/or generate crime (Brantingham \& Brantingham, 1995). Crime generators pull "masses of people who without any predetermined criminal motivation stumble upon an opportunity too good to pass up". Motivated offenders are drawn to crime by known criminal opportunities in particular places-these places are crime attractors (Franka et al., 2011, p. 1). We also provide examples of public places that are criminogenic because they offer the right conditions for anonymity, which is essential for certain types of crime. Robbery, rape, and even violations such as the dumping of garbage and chemicals, for instance, only happen in places with poor surveillance and reduced opportunities for intervention (Ceccato \& Uittenbogaard, 2014; Pettiway, 1982). These are characteristics of forests, desolated places, and roadsides that can make certain types of targets more vulnerable to victimization than others can (see the chapter about the role of public places in Disability Hate Crimes, for example). Desolate places in a park can also be pointed out as places that trigger fear and anxiety among park users.

Even when crime does not happen in a particular public place, if an individual feels unsafe in that place, that person may avoid it at particular times of the day or altogether (Ceccato, 2012, 2013). We show in this book that this is problematic because, in some cities, especially those in the Global South, a large percentage of the population, often women, spend much of their time in public places. They are "transit captives": they have relatively less access to non-public forms of transportation and are, therefore, overly reliant on public transport and spend much of their time in public places. The cross-cutting theme The movement will focus on "the dynamics of crime and fear in the transit city" and it constitutes a fundamental part of the book. A particular concern of women is the fear of sexual harassment while travelling, a concern that seems universal, as incidents of sexual harassment are reported on buses and trains in cities around the world (Ceccato \& Loukaitou-Sideris, 2020). If public transportation is not reliable or safe, women's mobility is impaired. Although women are most often the target of these types of behavior, they are not the only victims. There is evidence that gay men and transgendered persons are often victims of sexual harassment and violence in the São Paulo metro (Ceccato \& Paz, 2017) and other cities in the world (Gekoski et al., 2015).

An individual's right to safe public places is also highly dependent on society's norms and structures, whether they promote or limit one's freedom to move around without hindrance or fear. The risk of being a victim of crime and individual perceptions of personal safety are not only issues related to one's age or gender but result from the intersection of a set of individual characteristics. In this book, we examine victimization and fear through an intersectional lens, considering issues of gender and age in particular in the cross-cutting theme The users' perspective. Being an older and poor person creates "synergic layers 
of disadvantage" that affect whether one is at risk of being a victim of crime and how one experiences the world and expresses fear. This part also includes the perspective of victims of crimes as well as the offenders.

The book's contributions illustrate new ways of measuring crime and/or perceived safety in public places. In Part V, The metrics, data about public places have been an important element in the discovery of patterns of regularities of both crime and fear in city environments. Equally important has been the use of spatial analysis for planning purposes, particularly when the goal has been to focus resources-more precisely, to tackle unsafe places and formulate preventive actions. The potential of these analyses is directly linked to the technological development of place-based techniques as well as use of "big data" both in academia and among planners and other professionals.

In particular, this book examines the evidence of victimization of crime in public places, feelings of perceived safety or lack thereof, and the necessary improvements that can make these places safer. The cross-cutting theme The intervention provides concrete examples of practices to guide public policy and local practices. Examples of collaborative safety planning strategies that aim at improvements of safety through local governance around the world make up this part. These chapters provide better grounds to assess the risk of crime and perceived fear that can help urban planners to better plan public places.

\subsection{Steps taken in the making of the book}

In order to create a cohesive edited volume, the authors met in Stockholm, Sweden, on 19 October 2018, to discuss the scope and structure of the book, as well as the particularities of the cities and countries. This meeting followed the conference "Crime and Fear in Public Places: Patterns, Challenges and Actions" that took place in Stockholm, Sweden, 17-18 October 2018, where researchers presented their results in seven parallel sessions.

All chapters went through a blind peer review process with, on average, two reviewers per chapter (see the Acknowledgements for a list of reviewers) and were guided by a template of evaluation criteria from editors. With the sets of suggestions in hand, the authors had a chance to incorporate suggestions to the chapters and re-submit to editors-a process that took about six months to complete. From the original submissions, four contributions were eliminated during this process. This evaluation process ensured that book followed a basic structure in terms of size, geographical coverage and degree of multidisciplinarity. The book is perhaps the first publication devoted entirely to crime and fear of crime in public places from a truly international perspective. Since the majority of the current literature to date is dominated by North American and Western European study cases, this book opens up this field of research to other contexts and includes countries from Africa, Asia and Latin America, drawing from the experiences of cities in the Global North and the Global South. Specifically, the book contains contributions from Poland, Sweden, the United Kingdom, 
Mexico, India, Japan, Spain, Belgium, Australia, Italy, Brazil and the United States.

\subsection{Definitions and terms}

In this section, we define the most common terms used in this edited volume. This set of definitions and terms is expected to support the reading of the chapters that follow. What we mean by a particular term is not absolute and may slightly change from chapter to chapter. What we need to be aware of is that a definition bears a morality, which we argue, should better be spelled out, because whatever definition we assume has implications for how we, as researchers, approach a particular issue.

Let's take the case of public places. Why is it so important to think about the concept of public places? First, because our focus in this special book is on the circumstances of crimes in these public arenas, namely, common, shared environments (often non-virtual) that can be accessed by individuals often at all times, such as parks, pedestrian paths, tunnels, streets, interstitial spaces between buildings, transport nodes such as bus stops, surrounding areas, public places in neighborhoods. Second, crime-and the nature of each crime-depends on where the offense takes place. Open public spaces by their nature are perfect for pickpocketing but not for robbery; the former demands a crowd, the latter requires anonymity, sometimes characteristics of some desolated public places. Third, it is important to reflect upon the concept of public place because offense definitions (and offense seriousness) are determined by the situational conditions of crime. Whether a crime happens in a domestic, private environment or in the public realm is information that serves to support the work of the police. For instance, 'indoors' are considered places where order and crime cannot be affected by police surveillance or where any other type of intervention of the police is limited; for example, in premises of various kinds, dwellings, workplaces, shops and entertainment. Regardless of the differences in legal definition of what a public place is in different contexts, if a crime happens in a public space, its seriousness is determined not only by the rules of publicness of that setting but also the extent these rules are put in practice by those who manage and consume this particular public space.

Public place is a general term used in this book to describe any place where individuals are victims of a crime, or a place that, by the physical and social characteristics of its environment, triggers fear of crime, anxieties and other safety concerns. Individuals have partial or full access in a public place, either under free conditions or payment, such as a shopping mall, a sports stadium, a park or a train platform. In this volume, a wide range of public places with varying degrees of access for the public are used as a reference for analysis, namely parks, streets, open drug scenes, interstitial places in neighborhoods, and bus stops as well as places on the way to them. Sometimes public places are used as a synonym for publically accessed spaces and places as 'neighborhoods' or 
'neighborhood contexts' (see Chapters 6, 13 and 20). In addition, how virtual social networks can mirror real public places is discussed.

Thus, in this book, the term public place is distinct from the general concept of public space, which is often used in architecture and urban planning to indicate open areas, green areas, town squares, large interstitial spaces in which individuals may move freely, where entry is in some way unrestricted. Some authors define public space as, for instance, the 'space that is not controlled by private individuals or organizations, and therefore is open to the general public' (Madanipour, 1996, p. 144). Costamagna et al. (2019, p. 133) suggest

a public space is a place that is characterized by a collective social use and is freely accessible and usable by everyone. Such spaces can be either indoors or outdoors, and may include walkways, parks and other open areas like public squares, public building lobbies and various other areas where people can sit, gather or pass through.

Overall, almost all definitions of and views about public space include the primary indicators of accessibility and activity, stating that urban public space is an area that is accessible to all people and is the setting for their activities (Costamagna et al., 2019, p. 135). In reality, the two terms public place and public space have been used interchangeably in the literature (Ceccato, 2016, 2017; Hadavi, Kaplan, \& Hunter, 2018; Németh, 2012) and their definitional boundaries are often blurred, as also in this edited volume. For more details, see Ceccato (2015). On a more practical note, what is important to remember is that what constitutes a public place is highly context dependent. The conditions in a winter day in the streets of Lagos, Manilla or Sao Paulo are not the same as those found in cities of the Nordic countries, with long, cold, dark days. Gehl (2013) reminds us that cities must be lively, safe, sustainable and healthy, but these are hard conditions to achieve in northern cities in the winter. Public spaces are the places where most human social relations take place and are indeed particularly important for individual's health. In addition, "the presence of inclusive public spaces that accommodate the needs of a multitude of people, who may not otherwise cross paths in their daily lives, is therefore essential to a rich public life and an integrative society" (Costamagna et al., 2019, p. 134).

Social sustainability is one of the three dimensions of sustainability, the others being economic and environmental, and is the least defined and least understood. Richard, Johansson, and Salonen (2015) define it as the capacity of a society to tackle complex societal issues and its resilient ability to continuously function as a social system. A socially sustainable city, they suggest, can only be achieved if it builds mutual trust through public places that allow for people to feel self-confident without fear and discrimination.

Governance refers to all processes of governing, whether by a government, market, or network, whether over a formal or informal organization, or territory, and whether laws, norms, power or language (Bevir, 2012). 


\section{Vania Ceccato et al.}

Victimization and safety perceptions. In this book we adopted the two UNHabitat dimensions of safety and security: actual and perceived. Actual safety/ security refers to the risk of becoming a crime victim, measured by a variety of metrics and crime statistics, while perceived safety/security refers to people's safety perception through the lens of fear and anxiety. In many cases, urban dynamics and socio-spatial characteristics have an influence on whether a city has high levels of crime and violence. Spatial, social and economic fragmentation and exclusion feed insecurity and vice versa (UN-Habitat, 2019). Safety also depends on what happens in these places, and in turn what happens in them depends on how safe these places are perceived to be (Ceccato, 2016). Poor perceived safety has also been linked to public perceptions of disorder, which in turn have also been associated with serious crimes, implicit stereotypes about ethnic background and social efficacy (Sampson \& Raudenbush, 2004). Acts of disorder function as symbols of the extent to which an area is in decline or that nobody is in control (Lewis \& Maxfield, 1980). If people feel a lack of social control, this may decrease the walkability of streets and indirectly affects their health conditions (Branas et al., 2011).

Public transport or public transportation is the term used here to capture what North American readers often call "public transit", "mass transit" or "rapid transit" systems (Newton, 2014, p. 709). These systems, such as trains, buses, trams, comprise forms of transport that are available to the public, charge set fares, and run on fixed routes. In this book, the type of transit systems may vary from city to city.

Sexual offenses and crimes can be a vast array of sexual behaviors that range from sexual harassment to sexual assault. The boundaries between these types of acts are blurred. As early as in the 1990s, Cohan and Shakeshaft (1995) distinguished between what they called "noncontact" and "contact" sexual violence. In the noncontact category, they included nonverbal sexual abuse and verbal sexual abuse, while in the contact category, they included sexual abuse such as touching, kissing and rape. For more details see Ceccato and Loukaitou-Sideris (2020).

Whole journey approach (Natarajan, Schmuhl, Sudula, \& Mandala, 2017) includes walking to and from the public transportation (bus stops, train stations) as well as waiting for and riding on the bus or subway, it is the trip from door-to-door.

Intersectionality is an approach that considers the multiple identities of the population in order to tie them through categories that allow the identification of interactions between such identities and the activities or experiences of individuals (Levin, 2015). More specifically, however, the intersectionality approach is often in response to certain conditions that represent oppression: power relations, inequalities, justice in different social contexts (Hopkins, 2017).

\subsection{Chapter synopses}

The book that follows is composed of seven parts and 23 chapters. Part I consists of three chapters: following this introductory chapter, which presents the 
subject area, definitions, and scope, Chapter 2 discusses a number of criminological theories that provide the theoretical background for the chapters of the book. Chapter 3 presents the research evidence on crime and fear in public places, focusing on three main aspects of design and security technology (lighting, CCTV and CPTED). This initial part motivates why crime and fear in public places are worthy topics and presents the aim of the book, the scope, the five cross-cutting themes (Parts II to VI), the theory and the delimitations.

Part II portrays the city environments as the backdrop for crime and fear in different types of public places, such as parks. The first chapter of this Part, Chapter 4 , is devoted to general evidence of the importance of the physical environment for crime and perceived safety in parks using CPTED as a theoretical framework while Chapter 6 is a literature overview about the role of public places for hate crimes towards individuals with disabilities.

Part III offers examples of transit safety with a focus on sexual crime against young people (university students) deriving from four case studies: Mexico City, Mexico; Tokyo/Kanagawa, Japan; Rio Claro, Brazil; and Lagos, Nigeria. We report the results from a recent survey focusing on the experiences of victimization, in particular sexual crimes and perceived safety among university students, which was part of a global investigation conducted in conjunction with other cities by researchers from six continents (Ceccato \& Loukaitou-Sideris, 2019). We focus on university students because the majority of the victims of sexual harassment in transit are young people (Beller, Garelik, \& Cooper, 1980), they are more similar to each other in age than the general population, and, since they have lower car ownership rates than the rest of the population, they have to rely on public transportation more extensively than do other urban residents. Lastly, we also had a practical motivation to focus on college students, as we could reach them more easily than other groups through their universities. Focus is placed on the relationship between safety and the types of environments that individuals are exposed to when they travel, which means that the book adopts a whole journey approach to safety.

One of the novelties of this book is that a few contributions deal with users, the people who "consume" public places. They may sometimes become a victim of crime, sometimes are the offenders or, just by their presence, may prevent crime from happening. Part IV is devoted to patterns of victimization and perceived safety by specific groups of city users. The chapters highlight the differing needs of these groups but also the role of public spaces on offending. This Part starts with a theoretical piece about sexual harassment in public places and women's safety work followed by an analysis of sexual victimization and offending patterns in India. More specifically, the concordance rates between victims and offenders of sexual harassment as well as offenders and their male friends' sexual harassment offending patterns is examined. Chapters 13 and 14 deal with the importance of neighborhood context to individual's perceived safety: one is focused on older adults' patterns of perceived safety and the other on women's fear, in particular the interplay between individual and environmental factors in impacting fear. 


\section{Vania Ceccato et al.}

Part V, the metrics, focuses on methods and new data sources for assessing patterns of crime and fear in public places. The first chapter describes a pilot of Ecological Momentary Assessment to assess contextual determinants of fear of crime followed by, Chapter 16, which looks at a combination of quantitative and qualitative techniques to map and evaluate the nature of Open Drug Scenes (ODS). The final contribution makes use of data coming from social media to describe fear in cyberspace. In the digital age, "eyes" are complemented by technologies such as smartphones, "apps," or body-worn cameras, giving expression to new ways of depicting what happens in public space (Ceccato, 2019; Gibson, 2014). In this book, this chapter goes beyond the concrete, tangible arenas such as parks and streets and is devoted instead to virtual public places. The contribution focuses on the phenomenon of fear in cyberspace, through the analysis of emotional linguistic responses of online social media using "big data": a sample of more than two million tweets collected on three occasions: after the attacks on Charlie Hebdo, at Nice, and at Barcelona between 2015 and 2017.

Part VI offers four examples of current practices in promoting safety for different groups of society, both by academics and practitioners. The first chapter in this Part focuses on a particular feature of the urban environment that is traditionally associated with declared levels of fear: street lighting. This contribution critically reflects upon the impact of street lighting on crime and the fear of crime, with a particular emphasis on the effect of reduced street lighting, using as a reference studies published since the 1960s on this subject. The second chapter turns our attention to the night-time economy and, in particular, the music festival context to evaluate harm-reduction initiatives in the UK. Part VI also illustrates a case study in social capacity building from the New Orleans neighborhood following Hurricane Katrina, in the US. Using an action research case study approach, the journey of residents in rebuilding their neighborhood is described, focusing on a ten-year period beginning with initial community initiatives in 2008 and subsequent programs in the following years. Finally, Chapter 21 looks at urban planners' practices with regards to safety issues in municipalities in Sweden, based on answers from surveys collected from 85 percent of municipalities in Sweden in 2019.

Part VII brings together this edited volume, and highlights and summarizes the main findings presented in the book, based on each of the preceding sections. Based on the literature and the empirical findings, Part VII answers two important questions: assessing the nature of fear of crime in public places globally, and what can cities do to reduce crime and fear through research, design and policy? These final chapters discuss the findings comparatively and their implications for theory and practice, then suggests a future research agenda. How do we make public places safer for various types of city users? In different city and country contexts following an agenda aligned to the 2030 Agenda for Sustainable Development?

The book concludes by stating the need for urban policy integration taking into account the relationship between the urban environment and safety and 
social sustainability of cities; individual's safety from an intersectional lens; and individual's mobility from the perspective of a whole journey approach in Global North-South contexts, in urban areas and smaller settlements, often in tangible spaces but also, and more often than even before, interconnected to virtual public spaces. Interventions ought to be inclusive, engaging and backed up by long-term democratic processes that lead to change, and aimed at creating safe and sustainable environments for all. In the end, urban development emerges from prosperity, through adequate and sound evidence-based planning, management and governance; it comes to be fully enjoyed once urban safety is guaranteed.

\subsection{Concluding remarks}

The aim of the book is to characterize with examples from all around the world the dynamics of crime and fear in public places depicted by five crosscutting themes: environment, movement, city users' perspective, metrics and interventions. Emphasis is given to the relationship between safety and the types of environments that individuals are exposed to, but also the impact of a lack of perceived safety and its potential determinants. In addition, this book examines the evidence of victimization and fear in public places from an interdisciplinary perspective, with examples from the Global North-South contexts, considering theories at the crossroads of several disciplines, such as environmental criminology, architecture and design, urban planning, geography, psychology, gender and LGBTQI studies, transportation, data science, engineering, linguistics, and law enforcement. The book can, therefore, be a resource for academics and students in urban planning, criminology, geography, and sociology, by professionals in police and law enforcement and transportation, and for policymakers and city planners interested in ensuring safe travel in their cities. Thus, this book is targeted at both researchers and practitioners with a hope to invite and encourage greater inter- and multi-disciplinary dialogue.

\section{References}

Beller, A., Garelik, S., \& Cooper, S. (1980). Sex crimes in the subway. Criminology, $18,35-52$.

Bevir, M. (2012). Governance: A Very Short Introduction. Oxford: Oxford University Press.

Branas, C. C., Cheney, R. A., MacDonald, J. M., Tam, V. W., Jackson, T. D., \& Ten Havey, T. R. (2011). A difference-in-differences analysis of health, safety, and greening vacant urban space. American Journal of Epidemiology, 174, 1296-1306.

Brantingham, P. L., \& Brantingham, P. J. (1995). Criminality of place: Crime generators and crime attractors. European Journal on Criminal Policy and Research, 3, 1-26.

Ceccato, V. (2012). The urban fabric of crime and fear. In V. Ceccato (Ed.), The Urban Fabric of Crime and Fear (pp. 1-33). Dordrecht, Heidelberg, New York, London: Springer Netherlands.

Ceccato, V. (2013). Moving Safely: Crime and Perceived Safety in Stockholm's Subway Stations. Plymouth: Lexington. 


\section{Vania Ceccato et al.}

Ceccato, V. (2015). Public space and the situational conditions of crime and fear. International Criminal Justice Review, 26, 69-79.

Ceccato, V. (2016). Public space and the situational conditions of crime and fear. International Criminal Justice Review, 26, 69-79.

Ceccato, V. (2017). Women's transit safety: Making connections and defining future directions in research and practice. Crime Prevention and Community Safety, 19, 276-287.

Ceccato, V. (2019). Special issue: Crime and control in the digital era. Criminal Justice Review, 44, 5-10.

Ceccato, V., \& Loukaitou-Sideris, A. (2019). Transit Safety among College Students: An International Study. www.kth.se/abe/om-skolan/inst/som/avdelningar/urbana-studier/ forskning/urban-community-sa/trygghet-i-kollektiv (accessed 14 February 2020).

Ceccato, V., \& Loukaitou-Sideris, A. (2020). Transit Crime and Sexual Violence in Cities: International Evidence and Prevention. London: Routledge.

Ceccato, V., \& Paz, Y. (2017). Crime in São Paulo's metro system: sexual crimes against women. Crime Prevention and Community Safety, 19(3), 211-226.

Ceccato, V., \& Uittenbogaard, A. C. (2014). Space-time dynamics of crime in transport nodes. Annals of the Association of American Geographers, 104, 131-150.

Clarke, R. V. (1997). Situational Crime Prevention: Successful Case Studies. New York: Harrow and Heston.

Cohan, A., \& Shakeshaft, C. (1995). Sexual Abuse of Students by School Personnel. https://digitalcommons.molloy.edu/edu_fac/10 (accessed 13 February 2020).

Costamagna, F., Lind, R., \& Stjernström, O. (2019). Livability of urban public spaces in northern Swedish cities: The case of Umeå. Planning Practice \& Research, $34,131-148$.

Franka, R., Vahid, D., Reida, A., Singhb, S., Cinnamona, J., \& Brantingham, P. (2011). Power of criminal attractors: Modeling the pull of activity nodes. Journal of Artificial Societies and Social Simulation, 14.

Gehl, J. (2013). Cities for People. Washington, DC: Island Press.

Gekoski, A., Jacqueline, M., Gray, M. H., Horvath, S. E., Aliye, E., \& Adler, J. (2015). 'What Works' in Reducing Sexual Harassment and Sexual Offences on Public Transport Nationally and Internationally: A Rapid Evidence Assessment. www.mdx.ac.uk/ data/assets/pdf_file/0019/155800/What-Works-in-Reducing-Sexual-Harassmentand-Sexual-Offences-on-Public-Transport-Nationally-and-Internationally.pdf (accessed 20 February 2020).

Gibson, T. A. (2014). In defense of law and order: Urban space, fear of crime, and the virtues of social control. Journal of Communication Inquiry, 38, 223-242.

Hadavi, S., Kaplan, R., \& Hunter, M. R. (2018). How does perception of nearby nature affect multiple aspects of neighbourhood satisfaction and use patterns? Landscape Research, 43, 360-379.

Hopkins, P. (2017). Social geography I: Intersectionality. Progress in Human Geography, 43(5), 937-947.

Levin, L. (2015). Gender equality and safety, a challenge for transport planning: Moving away from stereotypes and stereotypical attitudes and habits. In Newton, A. and Ceccato, V. (Ed.), Safety and Security in Transit Environments. Crime Prevention and Security Management (pp. 309-327). London: Palgrave Macmillan.

Lewis, D. A., \& Maxfield, M. G. (1980). Fear in the Neighborhoods: An investigation of the impact of crime. Journal of Research in Crime and Delinquency, 17, 160-189.

Madanipour, A. (1996). Design of Urban Space. New York: Wiley.

Natarajan, M., Schmuhl, M., Sudula, S., \& Mandala, M. (2017). Sexual victimization of college students in public transport environments: A whole journey approach. Crime Prevention and Community Safety, 19, 168-182. 
Németh, J. (2012). Controlling the commons: How public is public space? Urban Affairs Review, 48, 811-835.

Newton, A. (2014). Crime on public transport. Encyclopedia of Criminology and Criminal Justice (pp. 709-720). London: Springer.

Pettiway, L. E. (1982). Mobility of robbery and burglary offenders: Ghetto and nonghetto spaces. Urban Affairs Review, 18, 255-270.

Richard, E., Johansson, M., \& Salonen, T. (2015). Reflections on the right to health. In M. J. E. Richard, \& T. Salonen (Eds.), Social Transformations in Scandinavian Cities: Nordic Perspectives on Urban Marginalization and Social Sustainability (pp. 251-264). Lund, Sweden: Nordic Academic Press.

Sampson, R. J., \& Raudenbush, S. W. (2004). Seeing disorder: Neighborhood stigma and the social construction of "broken windows". Social Psychology Quarterly, 67, 319-342.

Sherman, L. W., Gartin, P. R., \& Buerger, M. E. (1989). Hot spots of predatory crime: Routine activities and the criminology of place. Criminology, 27, 27-56.

UN-Habitat (2013). Creating Safe Public Spaces. www.unwomen.org/en/what-we-do/ ending-violence-against-women/creating-safe-public-spaces (accessed 14 February 2020).

UN-Habitat (2017). Safe Cities Global Initiatives. UN, 2. www.unwomen.org (accessed 14 February 2020).

UN-Habitat (2019). Safer Cities Programme. https://fukuoka.unhabitat.org/programmes/ detail04_01_en.html (accessed 14 February 2020).

United Nations (2019). The Sustainable Development Goals. www.un.org/sustainable development/sustainable-development-goals/ (accessed 14 February 2020). 